\title{
Phytofabrication of iron nanoparticles and their catalytic activity
}

\author{
Edwin Shigwenya Madivoli ${ }^{1}$ - Patrick Gachoki Kareru ${ }^{1} \cdot$ Anthony Ngure Gachanja ${ }^{1} \cdot$ Samuel Mutuura Mugo $^{2}$. \\ David Sujee Makhanu ${ }^{3}$
}

(c) Springer Nature Switzerland AG 2019

\begin{abstract}
Metallic nanoparticles that have photocatalytic activity can be synthesized using aqueous plant extracts. The aim of this study was to synthesize iron nanoparticles using Lantana trifolia extracts and to evaluate their ability to degrade Congo red dye. The nanoparticles were characterized using UV-Vis spectrophotometer (UV-Vis), Fourier transform infrared spectrophotometer, wide angle X-ray diffractometer, dynamic light scattering, transmission electron microscopy (TEM), and thermal gravimetric analyzer to determine the functional groups, thermal properties, crystalline phases and diameter distribution of the particles. Cyclic voltammetry was used to evaluate the redox potential of the extracts while photocatalytic activity of the nanoparticles was evaluated using a UV-Vis spectrophotometer. Functional groups analysis revealed presence of secondary metabolites having $\mathrm{OH}$ and $\mathrm{C}=\mathrm{C}$ groups while a redox potential of $+0.3 \mathrm{~V}$ was an indication that the extracts can reduce iron. The presence of sharp peaks at $2 \theta$ values of $19.87^{\circ}, 20.22^{\circ}, 22.88^{\circ}, 28.81^{\circ}$, $32.73^{\circ}, 35.32^{\circ}, 38.45^{\circ}, 40.23^{\circ}$ and $41.08^{\circ}$ correspond to cubic crystal system of iron nanoparticles while particle aggregation was observed on TEM micrographs which also indicated that they were less than $200 \mathrm{~nm}$. In the presence of $\mathrm{H}_{2} \mathrm{O}_{2}$, the nanoparticles catalyzed degradation of Congo red dye in a first order reaction that was temperature dependent. In conclusion, secondary metabolites in L. trifolia can reduce metallic ion to iron nanoparticles which can degrade Congo red dye.
\end{abstract}

Keywords L. trifolia $\cdot$ Secondary metabolites $\cdot$ Iron nanoparticles $\cdot$ Photocatalyst

\section{Introduction}

Metallic nanoparticles have received great attention due to their unique physical, chemical and biological properties that makes them find applications in various fields such as medicine and in environmental remediation as photocatalysts [1]. During the past decade, many biological systems such as plants [2], algae [3], diatoms [4], bacteria [5], yeast [6], fungi [7], and human cells [8] have been used to transform inorganic metal ions into metal nanoparticles via the reductive capacities of the metabolites found in these organisms. For iron nanoparticles, several physical and chemical production methods including mechanical milling [9], sodium borohydride [10, 11], ethylene glycol [12], solvothermal method [13], and carbothermal synthesis [14] have been employed for their preparation [15]. Iron nanoparticles synthesized by these methods rapidly agglomerate to form clusters due to interparticle Van der waals and magnetic forces and may further undergo rapid oxidation [16, 17]. However, secondary metabolites found in plant extracts such as terpenoids, alkaloids, phenolic acids, polyphenols, sugars and

\section{Electronic supplementary material The online version of this article (https://doi.org/10.1007/s42452-019-0951-0) contains supplementary material, which is available to authorized users.}

Edwin Shigwenya Madivoli, edwinshigwenya@gmail.com $\mid{ }^{1}$ Chemistry Department, Jomo Kenyatta University of Agriculture and Technology, P.O. Box 62000-00200, Nairobi, Kenya. ${ }^{2}$ Chemistry Department, McEwan University, 10700-104 Avenue, Edmonton, AB T5J 4S2, Canada. ${ }^{3}$ Department of Physical and Biological Sciences, Karatina University, P.O. Box 1957-10101, Karatina, Kenya. 
proteins can play a significant role in the bioreduction of the $\mathrm{Fe}^{3+}$ ions to iron nanoparticles $[15,18]$. This synthesis approach does not require heating and the metabolites act as reducing and capping agents thereby protecting the nanoparticles formed from autooxidation [15, 18-20]. These biosynthesized iron nanoparticles have found significant importance in environmental remediation as catalyst for degradation of organic dyes, chlorinated organic pollutants and adsorbent for heavy metal removal. In the presence of $\mathrm{H}_{2} \mathrm{O}_{2}$, iron nanoparticles catalyze the production of free radicals which promote the increase in the rate of degradation of organic dyes [21]. Lantana trifolia or lantana as it is commonly referred to, is a highly invasive shrub thought to have been brought into Africa from Europe and it is usually harvested from the wild for its medicinal value, where it is used locally as a source of food, medicine and wood. GC-MS profile of the plans has revealed the presence of secondary metabolites such as nonanoic acid, Ethyl iso-allocholate, 1,7-octadien-3-ol, cis-3-Hexenoic acid, cis-3-hexenoic acid, 2-Nonen-1-ol, 3-cyclopropyl-7-hydroxylmethyl bicycle[4.1.0]heptane, Germacrene D among many other compounds [22]. The aim of this study was to synthesize iron nanoparticles using aqueous extracts from L. trifolia and to evaluate their ability to catalyze the degradation of Congo red dye. The influence of temperature and contact time on the rate of degradation were evaluated using UV-Vis spectroscopy while the functional groups present, and thermal properties of the nanoparticles were investigated using Fourier Transform infrared spectroscopy and thermal gravimetric analysis. Wide angle X-ray diffractometer was used to evaluate the crystalline phases of the nanoparticles while TEM was used to determine their sizes.

\section{Materials and methods}

\subsection{Sample preparation}

Dry L. trifolia plant materials were collected from Juja, Kambu County in Kenya washed with distilled water and dried in the oven for $48 \mathrm{~h}$ at $70^{\circ} \mathrm{C}$. After cooling, the sample was finely ground (In-house fabricated mechanical grinder) and $100 \mathrm{~g}$ of the ground material was then mixed with $1000 \mathrm{ml}$ of distilled water, boiled for $5 \mathrm{~min}$, cooled and the solution filtered through a Whatman filter paper no. 1 . The extract was then stored in a refrigerator at $4{ }^{\circ} \mathrm{C}$ until further studies [23].

\subsection{Synthesis of iron nanoparticles}

To synthesize iron nanoparticles, the aqueous plant extract was mixed with $0.1 \mathrm{M} \mathrm{FeCl}_{3} \cdot 6 \mathrm{H}_{2} \mathrm{O}$ solution prepared in double distilled water in different ratio and concentration. For the reduction of $\mathrm{Fe}^{3+}$ ions, different volume of the aqueous plant extracts was then added slowly to the ferric chloride solution and vortexed (Vortex Genie 2, scientific industries, USA) for $3 \mathrm{~min}$ at room temperature. The formation of iron nanoparticles was indicated by a change in colour of the solution from light yellow to black [24]. The black precipitate was obtained through centrifugation at 1000 rpm (Hettich zentrifugen, Andreas Hettich group Tuttlingen, Germany) washed several times with MilliQ water and dried at $60^{\circ} \mathrm{C}$ in the oven until further analysis [18].

\subsection{Cyclic voltammetry}

In our study, voltammetric measurements were carried out using a Metroohm Autolab made up of a potentiostat-galvanostat equipped with NOVA 2.0 software [25-28]. The experiment was performed in a single-compartment Pyrex cell using a conventional three-electrode configuration. Two-millimeter glassy carbon disk working electrode (GCE) polished before each measurement, a platinum wire counter electrode, and an $\mathrm{Ag} / \mathrm{AgCl}$ saturated $\mathrm{KCl}$ reference electrode were used. Twenty milliliters of supporting solution were dispensed into an electrochemical cell followed by addition of appropriate volume of plant extracts. Cyclic voltammograms measurements were performed at positive potentials, at a scan rate of $100 \mathrm{mVs}^{-1}$ at room temperature in the presence of $\mathrm{KCl}(0.1 \mathrm{M})$ as a supporting electrolyte [25].

\subsection{Characterization of iron nanoparticles}

UV-Vis absorption analysis was carried out using a Shimadzu UV-Vis 1800 spectrophotometer (Shimadzu, Japan) in the range of $200-800 \mathrm{~nm}$ [1]. The functional groups present in the nanoparticles were determined using a Bruker Tensor II FT-IR spectrophotometer model (Bruker, Ettlingen, Germany). The $\mathrm{KBr}$ pellets of the samples were prepared by grinding $10 \mathrm{mg}$ of the samples with $250 \mathrm{mg}$ $\mathrm{KBr}$ (FT-IR grade) $[29,30]$. The thermal properties of FeNPs was evaluated using a Mettler Tolledo Thermal Gravimetric DSC/TGA 3 + system (Mettler-Toledo GmbH, Switzerland). $10 \mathrm{mg}$ of the sample was heated from 25 to $500{ }^{\circ} \mathrm{C}$ at $10 \mathrm{~min}^{-1}$ cooled to $25^{\circ} \mathrm{C}$. The crystalline phase was identified using STOE STADIP P X-ray Powder Diffraction System (STOE \& Cie GmbH, Darmstadt, Germany). The X-ray generator was equipped with a copper tube operating at $40 \mathrm{kV}$ and $40 \mathrm{~mA}$ and irradiating the sample with a monochromatic CuKa radiation with a wavelength of $0.1545 \mathrm{~nm}$ [31]. The particle size distribution, zeta potential and polydispersibility index of the FeNPs solution were measured using a Bechman Coulter DelsaMax pro Dynamic light scattering analyzer (Indianapolis, United States). TEM 
analysis was performed on a Tecnai G2 Spirit (Thermo Fischer scientific, Oregon USA) operated at $120 \mathrm{kV}$ equipped with veleta $2048 \times 2048$ wide angle and Eagle $4096 \times 4096$ bottom mount detectors. The dried iron nanoparticles were suspended in ultrapure water $(18 \mathrm{M} \Omega \mathrm{cm}$ Barnstead Genpure UV-TOC, Thermo Fischer scientific, Germany) and vortexed (Vortex Genie 2, scientific industries, USA) to obtain a solution of suspended nanoparticles. The solution was then drop casted in Carbon films 300 mesh (Electron microscopy science, CF300-CU) and dried to evaporate the solvent before TEM analysis.

\subsection{Photodegradation studies}

The ability of the synthesized nanoparticles to degrade Congo red dye under different reaction conditions was evaluated using UV-Vis spectrophotometer [32]. In $2.5 \mathrm{ml}$ of Congo red dye (50 ppm) $0.5 \mathrm{ml} \mathrm{H} \mathrm{O}_{2}(30 \% \mathrm{v} / \mathrm{v})$ was added to the reaction in a quartz cuvette followed by addition of $10 \mathrm{mg}$ of iron nanoparticles. Absorbance readings were taken at 2 min intervals until equilibrium was attained and the degradation efficiency was determined using the following equation:

Percent degradation $(\%)=\frac{A_{0}-A_{t}}{A_{o}} \times 100$

where $A_{0}$ is the dye absorbance before decolorization and $A_{t}$ is the dye absorbance after decolorization. The effect of temperature on degradation was investigated at different temperatures between 25 and $40^{\circ} \mathrm{C}$ under constant $\mathrm{pH}$ while the effect of time was studied for 120 min respectively [32].

\section{Results and discussions}

\subsection{Synthesis of iron nanoparticles}

Synthesis of iron nanoparticles involved variation of metal ion in solution and the volume ratio of the extract to the metal ions and the results are depicted in Fig. 1.

In the case of biological synthesis of nanoparticles, the aqueous metal ions are reduced and as a result a color change is the first qualitative indication that nanoparticles have been formed (Fig. 1) [33, 34]. Variation of the ratio of the extract to the iron solution revealed that the nanoparticles were synthesized when the volume of the extracts to that of the metal ion was high (Fig. 1). Changes in metal ion concentration revealed that at lower and higher concentrations, the solutions did not become turbid as no particles were formed at lower concentration while at higher concentration, the reducing capability of the extracts was

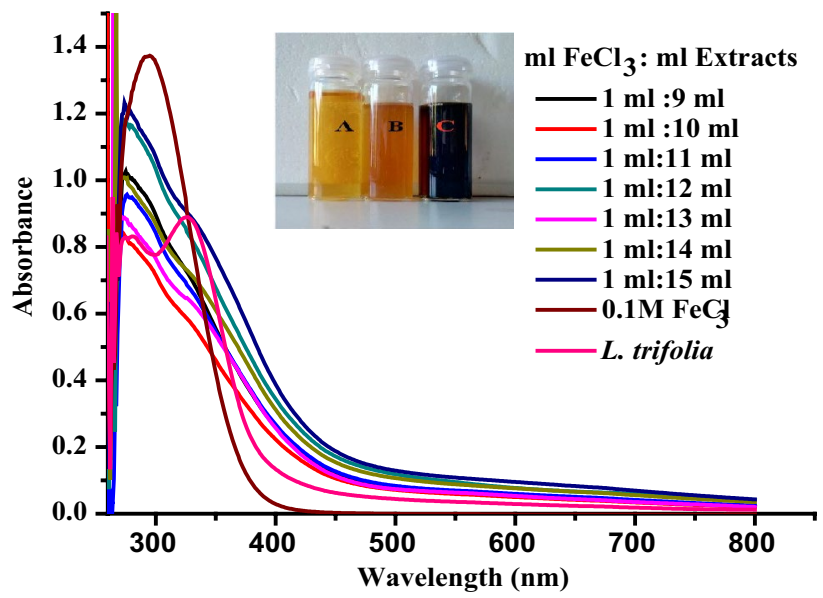

Fig. 1 UV-Vis spectrums showing variations of volume ratio of metal ion to volume of extracts used. Inset showing change in color of $\mathrm{FeCl}_{3}(\mathrm{~A})$, extracts (B) and nanoparticles (C)

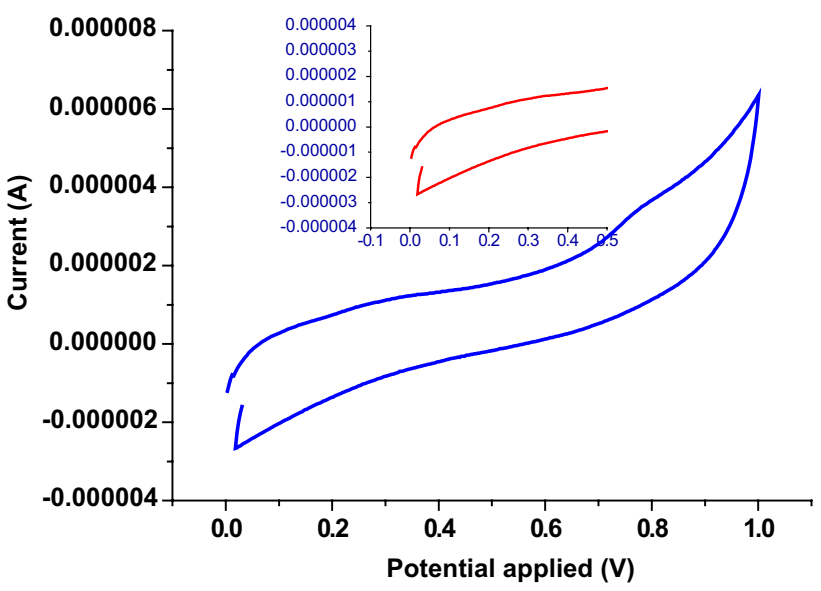

Fig. 2 Cyclic voltamogram of L. trifolia extracts showing the reduction potential

greatly reduced (Figure S1) [35]. Moreover, disappearance of the shoulder centered at $350 \mathrm{~nm}$ in the plant extract was only observed when the concentration of iron used was $0.1 \mathrm{M}$. The metal ion concentration is an important factor that needs to be considered and this may be adjusted by dilution $[21,36]$. The presence of chemically complex biomolecules, e.g., enzymes, amino acids, proteins, vitamins, and polysaccharides, and organic acids act as reducing and capping agents during synthesis [33].

\subsection{Measurement of redox potential of the extracts}

The redox potential of the extracts was measured against standard ascorbic acid and the results are depicted in Fig. 2. 


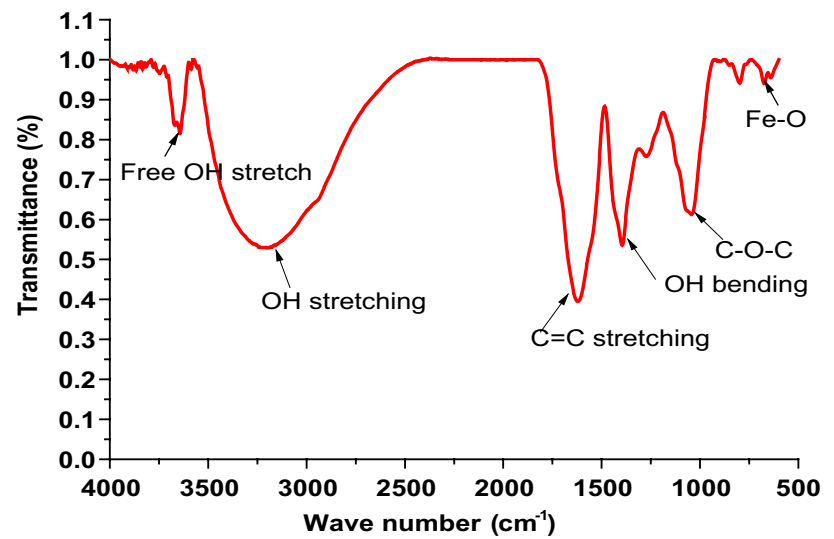

Fig. 3 FT-IR spectra of Iron nanoparticles synthesized using L. trifolia extracts

The extracts showed peak anodic currents at $+0.3 \mathrm{~V}$ and $+0.7 \mathrm{~V}$ an indication that they have strong free reducing capabilities as they are oxidized at relatively low potential [37]. The peak potential correlates with the type of reductant; low oxidation potentials are associated with a greater facility or strength of a given molecule to donate electrons $[38,39]$. The reduction potential of the plant extracts $(+0.7)$ was as a result of presence of polyphenols which make them able to reduce $\mathrm{Fe}^{3+}(+0.77)$ to $\mathrm{Fe}^{2+}[21$, 40]. However, the extract did not completely reduce the $\mathrm{Fe}^{3+}$ to zero-valent iron as they are strongly stabilized due to the presence of polyphenols ligands and they rapidly oxidize in the presence of oxygen to give $\mathrm{Fe}^{2+}$ polyphenol complexes in a phenomenon known as autoxidation (Fig. 5) [41]. Moreover, the reduction potential of $\mathrm{Fe}^{2+}$ to $\mathrm{Fe}^{0}$ is highly negative which implies that the plant extracts in the present study do not have the appropriate potential to reduce $\mathrm{Fe}^{3+}$ to $\mathrm{Fe}^{0}$.

\subsection{Determination of functional groups present}

The functional groups present in the phytomediated iron nanoparticles are depicted in Fig. 3.

From Fig. 3, the peak at 3650.53 and $3400 \mathrm{~cm}^{-1}$ can be attributed to $\mathrm{OH}$ stretching vibrations, while the peaks at $2925,1623.7,1415.3$ and $1024.6 \mathrm{~cm}^{-1}$ were attributed to $\mathrm{CH}_{2}, \mathrm{C}=\mathrm{C}, \mathrm{CH}, \mathrm{C}-\mathrm{O}-\mathrm{C}$ stretching vibrations of secondary metabolites such as terpenes and terpenoids present in L. trifolia extracts which acted as capping and stabilizing agents during synthesis. The appearance of a small peak at $678 \mathrm{~cm}^{-1}$ is due to the presence of iron-carbonyl complexes $(\mathrm{Fe}-\mathrm{C}=\mathrm{O})$ which confirmed the presence of secondary metabolite coating in the nanoparticles [42]. The results indicate that the plant polyphenols are part of the components in the iron nanoparticles and besides clinging on the surface of the particles they act as capping agents.

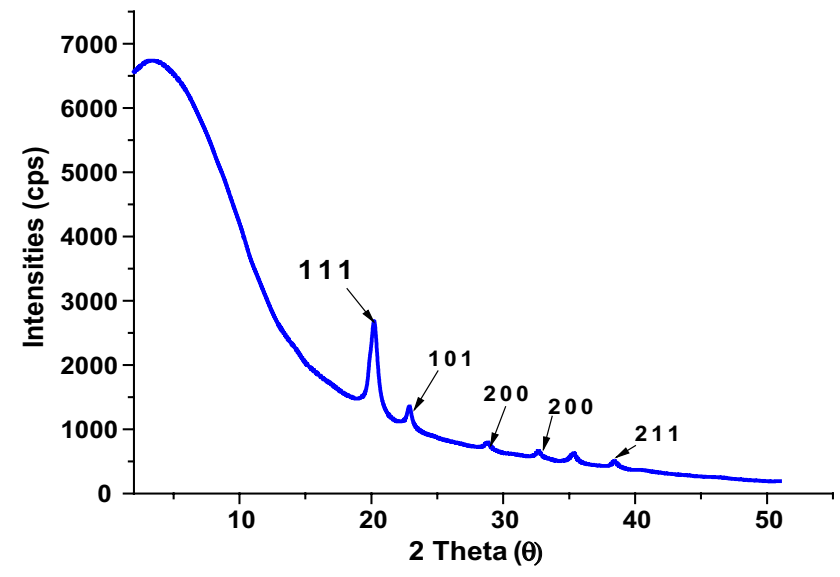

Fig. 4 X-ray diffractogram of iron nanoparticles synthesized using aqueous extracts of $L$. trifolia

Table $12 \theta$ values and $\mathrm{hkl}$ indices for phases identified

\begin{tabular}{llllll}
\hline No. & $2 \theta\left(^{\circ}\right)$ & $\mathrm{d}(\AA)$ & FWHM & Hkl (a) & Hkl (b) \\
\hline 1 & 19.87 & 2.0602 & 0.2640 & & $1,1,1$ \\
2 & 20.22 & 2.0246 & 0.5756 & $1,0,1$ & \\
3 & 22.88 & 1.7914 & 0.4014 & & $2,0,0$ \\
4 & 28.81 & 1.4283 & 0.4653 & $2,0,0$ & \\
5 & 32.68 & 1.2630 & 0.4064 & & $2,0,2$ \\
6 & 35.32 & 1.1714 & 0.5204 & $2,1,1$ & \\
7 & 38.45 & 1.0793 & 0.4694 & & $3,1,1$ \\
8 & 40.23 & 1.0333 & 0.4198 & & $2,2,2$ \\
9 & 41.08 & 1.0128 & 0.4166 & $2,0,2$ & \\
10 & 46.20 & 0.9058 & 0.3870 & & $4,0,0$ \\
11 & 46.27 & 0.9045 & 0.4702 & & \\
\hline
\end{tabular}

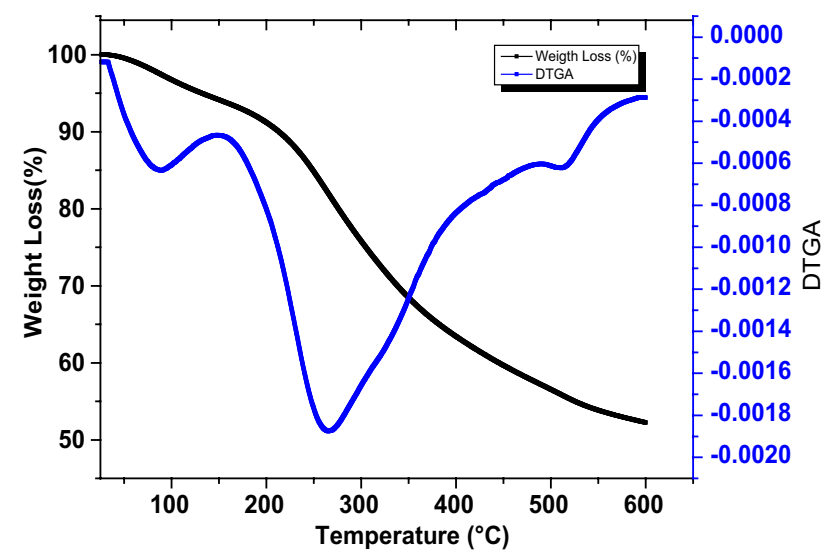

Fig. 5 TGA and DTGA thermograms of iron nanoparticles synthesized using $L$. trifolia extracts 
Similar results were observed when iron nanoparticles were synthesized with extracts from Eucalyptus tereticornis, Melaleuca nesophila, Rosemarinus officinalis and green tree extracts $[41,43]$.

\subsection{X-ray diffractogram of iron nanoparticles}

Single crystal X-ray diffractogram of iron nanoparticles synthesized are depicted in the Fig. 4.

From Fig. 4 and Table 1, the synthesized nanoparticle comprised of iron nanoparticles with a cubic crystal system. A search in the crystal data base revealed that the $2 \theta$ values at $19.87^{\circ}, 20.22^{\circ}, 22.88^{\circ}, 28.81^{\circ}, 32.73^{\circ}, 35.32^{\circ}$, $38.45^{\circ}, 40.23^{\circ}$ and $41.08^{\circ}$ correspond to cubic crystal system of iron nanoparticles as reported by $[44,45]$. The broad amorphous background was due to the secondary metabolites coating surrounding the iron nanoparticles which explains their role as capping agents [46]. At low FeNPs concentrations, the iron peaks are masked in XRPD due to a large amorphous background which impart the non-crystalline phases to the nanoparticles [36]. Similar observations have been made in a study in which identification of silver nanoparticles encapsulated with a silica shell with powder XRD was difficult due to the presence of an amorphous background $[47,48]$. Hence the dried powder of Fe-P NPs, which was prepared using L. trifolia extracts were organic and amorphous in nature [41].

\subsection{TGA and DTGA of iron nanoparticles}

The thermal property of iron nanoparticles was evaluated using thermal gravimetric analyzer (TGA) and DTGA and the thermograms are depicted in Fig. 5.

From Fig. 5, an initial weight loss observed at $100^{\circ} \mathrm{C}$ was attributed to loss of residual water adsorbed on the surface of the particles. The second degradation step centered at $250^{\circ} \mathrm{C}$ in DTGA can be linked to the decomposition of the organic layer around the particles. This decomposition makes the main peak in the DTGA curve which has been reported to be present as phyto mediated synthesis of nanoparticles affords them an organic capping layer $[33,49]$.

\subsection{Size distribution, zeta potential and poly-dispersibility index}

The size distribution, zeta potential and polydispersibility index were determined by dynamic light scattering (DLS) and the results are depicted in Fig. 6.

The results show that the average size of particle synthesized using L. trifolia extracts was in the range between 150 and $700 \mathrm{~nm}$ in diameter. DLS measures the hydrodynamic diameter, which is the diameter of the particle plus

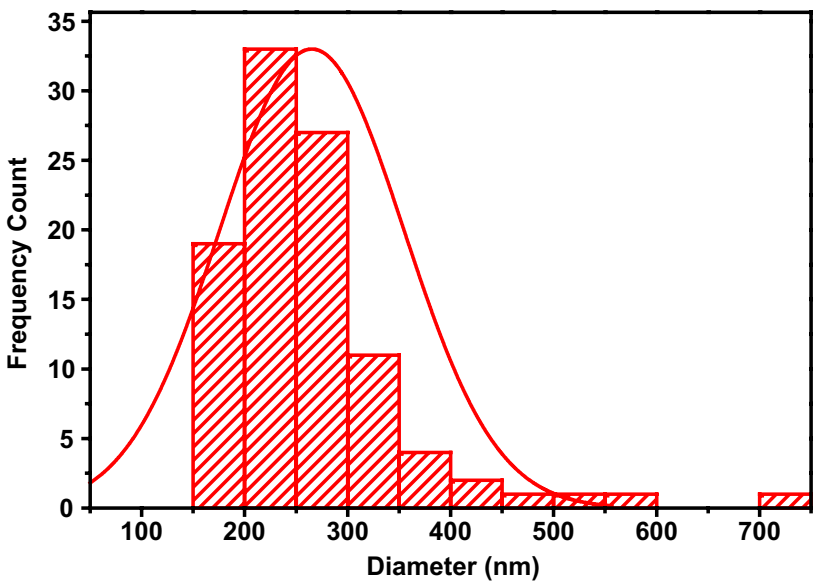

Fig. 6 Size distribution of iron oxide nanoparticles synthesized using $L$. trifolia extracts

ions or molecules that are attached to the surface and moves with the FeNPs in solution. The zeta potential and polydispersibility index of a given solution are important parameters that can be used to predict the stability and molecular mass distributions of nano emulsions. The value of zeta potential is related to the short- and long-term stability of emulsions where by émulsions with a high zeta potential (negative or positive) are electrically stabilized while emulsions with low zeta potentials tend to coagulate or flocculate, possibly leading to poor physical stability [50]. In this study, the PDI of synthesized nanoparticle was found to be $0.5607 \pm 0.045$ and Zeta potential was found to be $-0.10 \pm 0.08$ indicating that the particles tended to flocculate.

\subsection{TEM analysis of iron nanoparticles}

TEM micrographs of iron nanoparticles are depicted in Fig. 7.

From TEM micrographs, it was observed that the particles were aggregated possibly due to drying after synthesis, but an organic coating could be observed around them. Presence of this organic coating affords the amorphous nature of the nanoparticles which resulted to a large amorphous background in the diffractograms. Presence of aggregates posed a challenge in size determination of green synthesized nanoparticles as absence of single particles meant that use of image processing software wasn't possible though those that were measured lied between 200 and $500 \mathrm{~nm}$. Biosynthesized FeNPs were aggregated like grapes which was attributed to different components and concentrations of polyphenols in L. trifolia plant extracts, that played a key role in dictating the final structures and size of the nanoparticles [41]. 
Fig. 7 TEM micrographs of Iron nanoparticles synthesized using L. trifolia extracts

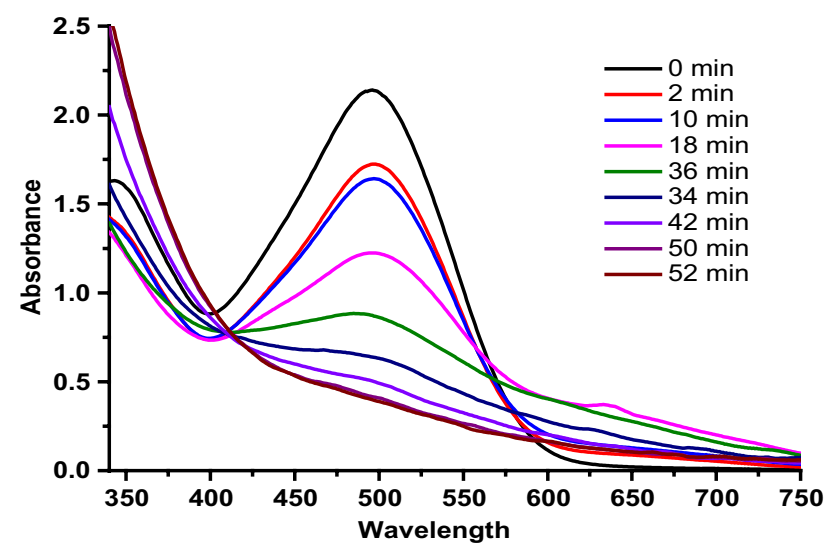

Fig. 8 Degradation of Congo red as a function of time at $30^{\circ} \mathrm{C}$

\subsection{Photocatalytic activity}

The effect of reaction time, temperature and amount of iron nanoparticles on Congo red degradation were evaluated and the results are depicted in Fig. 8 and figures S2-S4.

From Fig. 9 Table 2, degradation of Congo red dye using iron nanoparticles synthesized in this study was found to be dependent on the contact time between the nanoparticles and the temperature of the reaction media (Figure S3). With an increase in the temperature and time of the reaction, there was a subsequent increase in the rate of the reaction (Table 2) and percent degradation. At higher reaction temperatures, the nanoparticles were able to degrade Congo red dye by $91 \pm 0.03 \%$ as compared to lower reaction temperature $72 \pm 0.05 \%$. The reaction temperature also influenced the degradation rate as at higher temperatures the rate of the first order reactions was high (Table 2). The disappearance of the peak at $496 \mathrm{~nm}$ suggested that

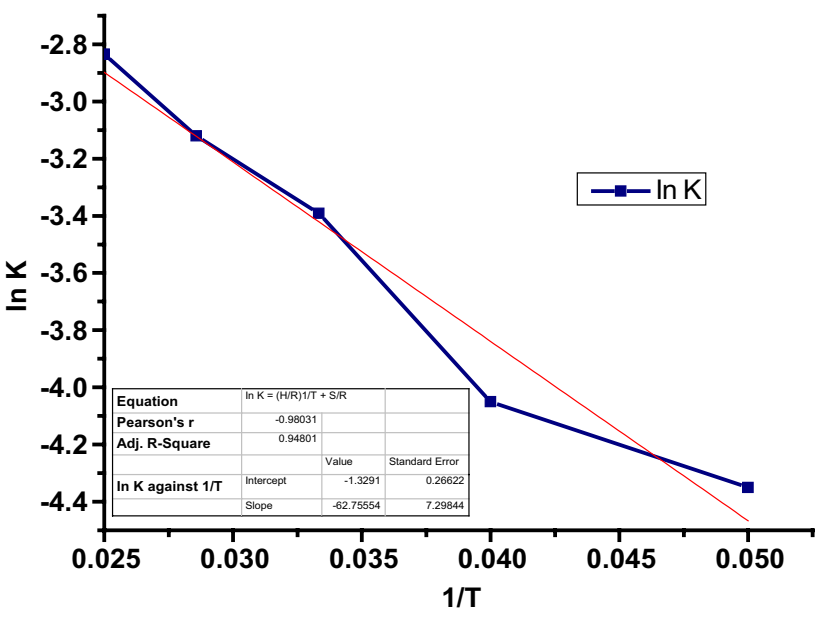

Fig. 9 Vant Hoff plots of In k against time (1/T)

Table 2 Rate of reaction ( $k$ ) for degradation of Congo red at different temperatures

\begin{tabular}{lllll}
\hline $\begin{array}{l}\text { Temperature } \\
\left({ }^{\circ} \mathrm{C}\right)\end{array}$ & $1 / \mathrm{T}$ & $\mathrm{k}$ & In $\mathrm{k}_{\mathrm{eq}}$ & Degradation (\%) \\
\hline 20 & 0.05 & 0.01 & -4.35 & 72.04 \\
25 & 0.04 & 0.02 & -4.05 & 66.93 \\
30 & 0.03 & 0.03 & -3.39 & 81.40 \\
35 & 0.03 & 0.04 & -3.12 & 85.81 \\
40 & 0.02 & 0.06 & -2.83 & 91.21 \\
\hline
\end{tabular}

the nanoparticles effectively degraded CR dye [32]. This observation is consistent with previous findings in which the degradation of malachite green using Bacillus cereus KM201428 was investigated [32]. The results obtained in this study at $30^{\circ} \mathrm{C}$ were used to determine the order of CR

\section{SN Applied Sciences}


degradation and the rate constants for the degradation of Congo red are depicted in Table 2. The results show that degradation of $C R$ dye using iron nanoparticles synthesised using $L$. trifolia extracts follow first order reaction kinetics since the correlation coefficient was highest for this model [32]. From the Van't Hoff plot of In K versus 1/T the degradation of Congo red was found to be an endothermic reaction since as the temperature increased the equilibrium constant for the reaction at the specified temperature also increased [51]. In the presence of $\mathrm{H}_{2} \mathrm{O}_{2}$, iron oxide nanoparticles are able to genereate $\mathrm{OH}$ and $\mathrm{O}$ radicals which are able to catalyze the degradation of organic dyes in solution.

\section{Conclusion}

Lantana trifolia extracts possess secondary metabolites that have a good redox potential that are able to reduce ferric chloride solution to corresponding iron nanoparticles which are further capped. Analysis of the synthesized nanoparticles revealed present of iron crystal structure that have been reported in literature and they comprised of an amorphous structure which was observed in diffractograms. Aggregation of the nanoparticles after drying led to an overall increase in the size of the nanoparticles as revealed by TEM analysis which also aided in the observation of capping as a result of presence of secondary metabolites. Degradation of Congo red dye followed a first order reaction rate which was greatly influenced by the temperature of the reaction media.

Acknowledgements The authors take this opportunity to acknowledge the National research fund, AFRICA-ai-JAPAN Project JFY 2018/2019, Jomo Kenyatta University of Agriculture, and Technology for their financial support and the Federal Swiss Government Scholarship for a 1-year research scholarship to the University of Fribourg under Prof. Katharina M. Fromm.

\section{Compliance with ethical standards}

Conflict of interest The authors declare that they have no conflict of interest.

\section{References}

1. Azam A, Ahmed AS, Oves M, Khan MS, Habib SS, Memic A (2012) Antimicrobial activity of metal oxide nanoparticles against Gram-positive and Gram-negative bacteria: a comparative study. Int J Nanomed 7:6003-6009

2. Mittal AK, Chisti Y, Banerjee UC (2013) Synthesis of metallic nanoparticles using plant extracts. Biotechnol Adv 31(2):346-356

3. Govindaraju K, Basha SK, Kumar VG, Singaravelu G (2008) Silver, gold and bimetallic nanoparticles production using single-cell protein (Spirulina platensis) Geitler. J Mater Sci 43(15):5115-5122
4. Scarano G, Morelli E (2002) Characterization of cadmium- and lead-phytochelatin complexes formed in a marine microalga in response to metal exposure. Biometals 15(2):145-151

5. Lengke MF, Fleet ME, Southam G (2007) Biosynthesis of silver nanoparticles by filamentous cyanobacteria from a silver (I) nitrate complex. Langmuir 23(5):2694-2699

6. Kowshik M, Deshmukh N, Vogel W, Urban J, Kulkarni SK, Paknikar KM (2002) Microbial synthesis of semiconductor CdS nanoparticles, their characterization, and their use in the fabrication of an ideal diode. Biotechnol Bioeng 78(5):583-588

7. Rautaray D, Ahmad A, Sastry M (2003) Biosynthesis of $\mathrm{CaCO}_{3}$ crystals of complex morphology using a fungus and an actinomycete. J Am Chem Soc 125(48):14656-14657

8. Anshup, Venkataraman JS, Subramaniam C, Kumar RR, Priya S, KumarTS, Omkumar RV, John A, Anshup T (2005) Growth of gold nanoparticles in human cells. Langmuir 21(25):11562-11567

9. Karimi EZ, Vahdati KJ, Zebarjad SM, Bataev IA, Bannovm AG (2014) A novel method for fabrication of Fe catalyst used for the synthesis of carbon nanotubes. Bull Mater Sci 2014:1031-1038

10. Woo H, Park J, Lee S, Lee S (2014) Effects of washing solution and drying condition on reactivity of nano-scale zero valent irons (nZVIs) synthesized by borohydride reduction. Chemosphere 97:146-152

11. Cai H, An X, Cui J, Li J, Wen S, Li K, Shen M, Zheng L, Zhang G, Shi $X$ (2013) Facile hydrothermal synthesis and surface functionalization of polyethyleneimine-coated iron oxide nanoparticles for biomedical applications. ACS Appl Mater Interfaces 5(5):1722-1731

12. Raveendran P, Fu J, Wallen SL (2003) Completely "green" synthesis and stabilization of metal nanoparticles. J Am Chem Soc 125(6):13940-13941

13. Basavaraja SD, Balaji D, Bedre MD, Raghunandan D, Swamy PP, Venkataraman A (2011) Solvothermal synthesis and characterization of acicular $\mathrm{a}-\mathrm{Fe}_{2} \mathrm{O}_{3}$ nanoparticles. Bull Mater Sci 34(7):1313-1317

14. Shen $Y$ (2015) Carbothermal synthesis of metal-functionalized nanostructures for energy and environmental applications. J Mater Chem A 3(25):13114-13188

15. Makarov VV, Love AJ, Sinitsyna O, Makarova SS, Yamnsky IV, Taliansky ME, Kalinina NO (2014) Green nanotechnologies: synthesis of metal nanoparticles using plants. Acta Nat 6(1):35-44

16. Huang G, Wang M, Hu Y, Lv S, Li C (2017) Synthesis, characterization, and debromination reactivity of cellulose-stabilized $\mathrm{Pd} / \mathrm{Fe}$ nanoparticles for 2,2',4,4'-tretrabromodiphenyl ether. PLoS ONE 12(3):1-17

17. Stanckic S, Suman S, Haque F, Vidic J (2016) Pure and multi metal oxide nanoparticles: synthesis, antibacterial and cytotoxic properties. J Nanobiotechnol 14(1):1-20

18. Sebastian A, Nangia A, Prasad MN (2018) A green synthetic route to phenolics fabricated magnetite nanoparticles from coconut husk extract: implications to treat metal contaminated water and heavy metal stress in Oryza sativa L. J Clean Prod 174:355-366

19. Herlekar M, Barve S, Kumar R (2014) Plant-mediated green synthesis of iron nanoparticles. J Nanoparticles 2014:1-10

20. Phan CM, Nguyen HM (2017) Role of capping agent in wet synthesis of nanoparticles. J Phys Chem A 121(17):3213-3219

21. Saif S, Tahir A, Chen Y (2016) Green synthesis of iron nanoparticles and their environmental applications and implications. Nanomaterials 6(11):2-26

22. Madivoli ES, Ondoo KO, Maina EG, Rugenyi F (2019) Phytochemical characterization, nutritional evaluation and GC-MS profiles of Lantana trifolia. Afr J Food Sci 2019:1-7

23. Kumar B, Smita K, Cumbal L, Debut A (2014) Biogenic synthesis of iron oxide nanoparticles for 2-arylbenzimidazole fabrication. J Saudi Chem Soc 18:364-369 
24. Kulkarni S, Jadhav M, Raikar P, Barretto DA, Vootla SK, Raikar US (2017) Green synthesized multifunctional Ag@ $\mathrm{Fe}_{2} \mathrm{O}_{3}$ nanocomposites for effective antibacterial, antifungal and anticancer properties. New J Chem 41(17):9513-9520

25. Keffous F, Belboukhari N, Sekkoum K, Djeradi H, Cheriti A, AboulEnein HY (2016) Determination of the antioxidant activity of Limoniastrum feei aqueous extract by chemical and electrochemical methods. Cogent Chem 2(1):1186141

26. Born M, Carrupt PA, Zini R, Bree F, Tillement JP, Hostettmann K, Testa B (1996) Electrochemical behaviour and antioxidant activity of some natural polyphenols. Helv Chim Acta 79(4):1147-1158

27. Simić A, Manojlović D, Segan D, Todorović M (2007) Electrochemical behavior and antioxidant and prooxidant activity of natural phenolics. Molecules 12(10):2327-2340

28. Kilmartin PA (2001) Electrochemical detection of natural antioxidants: principles and protocols. Antioxid Redox Signal 3(6):941-955

29. Ponce C, Chanona J, Garibay V, Palacios E, Calderon G, Sabo R (2013) Functionalization of agave cellulose nanoparticles and its characterization by microscopy and spectroscopy techniques. Microsc Microanal 19(S2):200-201

30. Madivoli ES, Maina EG, Kairigo PK, Murigi MK, Nyangau JO, Kimani PK, Kipyegon C (2018) In vitro antioxidant and antimicrobial activity of Prunus africana (Hook. f.) Kalkman (bark extracts) and Harrisonia abyssinica Oliv. extracts (bark extracts): a comparative study. J Med Plants Econ Dev 2(2):1-9

31. Katata-Seru L, Moremedi T, Aremu OS, Bahadur I (2018) Green synthesis of iron nanoparticles using Moringa oleifera extracts and their applications: removal of nitrate from water and antibacterial activity against Escherichia coli. J Mol Liq 256:296-304

32. Wanyonyi WC, Onyari JM, Shiundu PM, Mulaa FJ (2017) Biodegradation and detoxification of malachite green dye using novel enzymes from bacillus cereus strain KM201428: kinetic and metabolite analysis. Energy Procedia 119:38-51

33. Eslami S, Ebrahimzadeh MA, Biparva P (2018) Green synthesis of safe zero valent iron nanoparticles by Myrtus communis leaf extract as an effective agent for reducing excessive iron in iron-overloaded mice, a thalassemia model. RSC Adv 8(46):26144-26155

34. Truskewycz A, Shukla R, Ball AS (2018) Phytofabrication of iron nanoparticles for hexavalent chromium remediation. ACS Omega 3(9):10781-10790

35. Shah M, Fawcett D, Sharma S, Tripathy SK, Poinern GE (2015) Green synthesis of metallic nanoparticles via biological entities. Materials 8(11):7278-7308

36. Chekli L, Bayatsarmadi B, Sekine R, Sarkar B, Shen A, Scheckel KG, Skinner W, Naidu R, Shon HK, Lombi E, Donner E (2016) Analytical characterization of nanoscale zero-valent iron: a methodological review. Anal Chim Acta 903(2016):13-35

37. Amidi S, Mojab F, Moghaddam AB, Tabib K, Kobarfard F (2012) A simple electrochemical method for the rapid estimation of antioxidant potentials of some selected medicinal plants. Iran J Pharm Res 11(1):117
38. Hoyos-Arbeláez J, Vázquez M, Contreras-Calderón J (2017) Electrochemical methods as a tool for determining the antioxidant capacity of food and beverages: a review. Food Chem 221:1371-1381

39. Elgrishi N, Rountree KJ, McCarthy BD, Rountree ES, Eisenhart TT, Dempsey JL (2018) A practical beginner's guide to cyclic voltammetry. J Chem Educ 95(2):197-206

40. Somchaidee P, Tedsree K (2018) Green synthesis of high dispersion and narrow size distribution of zero-valent iron nanoparticles using guava leaf (Psidium guajava $L$ ) extract. Adv Nat Sci Nanosci Nanotechnol 9(3):1-9

41. Wang Z, Fang C, Megharaj M (2014) Characterization of ironpolyphenol nanoparticles synthesized by three plant extracts and their fenton oxidation of azo dye. ACS Sustain Chem Eng 2(4):1022-1025

42. Socrates G (2004) Infrared and Raman characteristic group frequencies: tables and charts. Wiley, West Sussex

43. Weng X, Huang L, Chen Z, Megharaj M, Naidu R (2013) Synthesis of iron-based nanoparticles by green tea extract and their degradation of malachite. Ind Crops Prod 51:342-347

44. Nishihara Y, Nakajima Y, Akashi A, Tsujino N, Takahashi E, Funakoshi KI, Higo Y (2012) Isothermal compression of face-centered cubic iron. Am Miner 97(8-9):1417-1420

45. Zhang J, Guyot $F(1999)$ Thermal equation of state of iron and Fe 0.91 Si 0.09. Phys Chem Miner 26(3):206-211

46. Markova Z, Novak P, Kaslik J, Plachtova P, Brazdova M, Jancula D, Siskova KM, Machala L, Marsalek B, Zboril R, Varma R (2014) Iron (II, III)-polyphenol complex nanoparticles derived from green tea with remarkable ecotoxicological impact. ACS Sustain Chem Eng 2(7):1674-1680

47. Priebe M, Widmer J, Lowa NS, Abram SL, Mottas I, Woischnig AK, Brunneto PS, Khanna N, Bourquin C, Fromm K (2017) Antimicrobial silver-filled silica nanorattles with low immunotoxicity in dendritic cells. Nanomed Nanotechnol Biol Med 13(1):11-22

48. Priebe M, Fromm KM (2015) Nanorattles or Yolk-Shell nanoparticles-What are they, how are they made, and what are they good for? Chem A Eur J 21(10):3854-3874

49. Ebrahiminezhad A, Zare-Hoseinabadi A, Sarmah AK, Taghizadeh S, Ghasemi Y, Berenjian A (2017) Plant mediated synthesis and applications of iron nanoparticles. Mol Biotechnol 60(2):154-168

50. Lu GW, Gao P (2010) Emulsions and microemulsions for topical and transdermal drug delivery. In: Kulkarni VS (ed) Handbook of non-invasive drug delivery systems. William Andrew Publishing, Norwhich, pp 59-94

51. Roy TK, Mondal NK (2017) Biosorption of Congo Red from aqueous solution onto burned root of Eichhornia crassipes biomass. Appl Water Sci 7(4):1841-1854

Publisher's Note Springer Nature remains neutral with regard to jurisdictional claims in published maps and institutional affiliations. 